\section{- OPEN ACCESS}

\title{
Prevention and treatment of colon cancer by peroral administration of HAMLET (human $\alpha$-lactalbumin made lethal to tumour cells)
}

\author{
Manoj Puthia, Petter Storm, Aftab Nadeem, Sabrina Hsiung, Catharina Svanborg
}

\begin{abstract}
- Additional material is published online only. To view please visit the journal online (http://dx.doi.org/10.1136/ gutjnl-2012-303715).

Department of Microbiology, Immunology and Glycobiology, Institute of Laboratory Medicine, Lund University, Lund, Sweden
\end{abstract}

\section{Correspondence to} Professor Catharina Svanborg, Department of Microbiology, Immunology and Glycobiology, Institute of Laboratory Medicine, Lund University, Sölvegatan 23, Lund 223 62, Sweden;

catharina.svanborg@med.lu.se

Received 9 September 2012 Revised 28 November 2012 Accepted 14 December 2012 Published Online First 24 January 2013

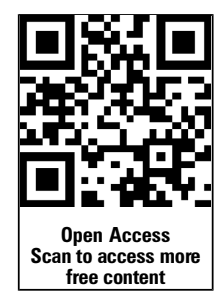

\begin{tabular}{l}
\hline To cite: Puthia M, Storm $P_{1}$ \\
Nadeem A, et al. Gut \\
2014;63:131-142.
\end{tabular}

\begin{abstract}
Background Most colon cancers start with dysregulated Wnt/ $\beta$-catenin signalling and remain a major therapeutic challenge. Examining whether HAMLET (human $\alpha$-lactalbumin made lethal to tumour cells) may be used for colon cancer treatment is logical, based on the properties of the complex and its biological context.
\end{abstract}

Objective To investigate if HAMLET can be used for colon cancer treatment and prevention. $\mathrm{Apc}^{\mathrm{Min} /+}$ mice, which carry mutations relevant to hereditary and sporadic human colorectal tumours, were used as a model for human disease.

Method HAMLET was given perorally in therapeutic and prophylactic regimens. Tumour burden and animal survival of HAMLET-treated and sham-fed mice were compared. Tissue analysis focused on Wnt/ß-catenin signalling, proliferation markers and gene expression, using microarrays, immunoblotting, immunohistochemistry and ELISA. Confocal microscopy, reporter assay, immunoprecipitation, immunoblotting, ion flux assays and holographic imaging were used to determine effects on colon cancer cells.

Results Peroral HAMLET administration reduced tumour progression and mortality in Apc $\mathrm{Min/+}^{\text {mice. HAMLET }}$ accumulated specifically in tumour tissue, reduced $\beta$-catenin and related tumour markers. Gene expression analysis detected inhibition of Wnt signalling and a shift to a more differentiated phenotype. In colon cancer cells with APC mutations, HAMLET altered $\beta$-catenin integrity and localisation through an ion channel-dependent pathway, defining a new mechanism for controlling $\beta$-catenin signalling. Remarkably, supplying HAMLET to the drinking water from the time of weaning also significantly prevented tumour development.

Conclusions These data identify HAMLET as a new, peroral agent for colon cancer prevention and treatment, especially needed in people carrying $A P C$ mutations, where colon cancer remains a leading cause of death.

\section{INTRODUCTION}

Colon cancers remain a major therapeutic challenge. Although the 5-year survival rate is extremely favourable after early detection and treatment of localised tumours, most colorectal cancers are either locally or distantly invasive at the time of diagnosis, limiting treatment options and lowering survival. ${ }^{1}$ About 160000 cases of colorectal cancer are diagnosed each year and 60000 patients die of the disease in the USA alone. ${ }^{2}{ }^{3}$ Worldwide, the number of deaths related to colon cancer has been estimated

\section{Significance of this study}

What is already known about this subject?

- Colon cancer accounts for about 600000 deaths annually, worldwide.

- More than $80 \%$ of sporadic and all hereditary colorectal tumours show a loss of function, owing to truncating mutations in the $A P C$ gene.

- Mice carrying the $A p c^{M i n /+}$ allele with a nonsense point mutation at nucleotide 2549 spontaneously develop multiple intestinal polyps. $A p C^{\mathrm{Min} /+}$ mice have therefore been extensively used as a model of familial and sporadic colorectal cancer.

- Inhibition of Wnt/ $\beta$-catenin signalling has therefore been proposed as a therapeutic approach in colon cancers.

- Human $\alpha$-lactalbumin made lethal to tumour cells (HAMLET) is a complex of $\alpha$-lactalbumin and oleic acid with broad antitumour activity.

\section{What are the new findings?}

- Peroral HAMLET administration acts therapeutically, by reducing the tumour burden and prolonging survival.

- Supplying HAMLET in the drinking water from weaning acts prophylactically and inhibits tumour development.

- HAMLET accumulates in intestinal tumours rather than in adjacent, healthy tissue.

- HAMLET suppresses $\beta$-catenin-dependent transcription.

- The effects of HAMLET were ion channel-dependent, defining a new mechanism modulating $\beta$-catenin signalling and survival in colon cancer cells.

\section{How might it impact on clinical practice in} the foreseeable future?

- Treatment of established colon cancer remains a major challenge. In addition, efficient preventive measures other than surgery are not available to families genetically prone to this disease. Here we identify HAMLET as a new, efficient therapeutic agent active against colon cancer. The results also suggest a new approach to colon cancer prevention.

by the WHO at about 600000 . The familial forms of colon cancer (familial adenomatous polyposis 
coli (APC)) are caused by a loss of APC function, often owing to truncating mutations in the gene, ${ }^{4}$ and more than $80 \%$ of all sporadic colorectal tumours show similar mutations. Tumour formation is initiated by a second, somatic mutation of the wild-type $A P C$ allele and with time, the tumours will accumulate additional mutations, affecting, for example, KRAS and $\mathrm{p} 53 .{ }^{4}$ The APC point mutation is sufficient for tumour initiation, however, and mice carrying the $A p c^{M i n /+}$ allele with a nonsense point mutation at nucleotide 2549 spontaneously develop multiple intestinal polyps. $A p c^{\mathrm{Min} /+}$ mice have therefore been extensively used as a model of familial and sporadic colorectal cancer. ${ }^{5}$

APC acts as a tumour suppressor by operating as a scaffold protein in the $\beta$-catenin destruction complex. Together with axin, casein kinase 1 (CK1) and glycogen synthase kinase 3 (GSK3), the APC complex phosphorylates the oncoprotein $\beta$-catenin for subsequent ubiquitination and proteasomal degradation. APC mutations reduce $\beta$-catenin proteolysis and enhance its nuclear translocation, ${ }^{6}{ }^{7}$ resulting in overactivation of the Wnt/ $\beta$-catenin signalling pathway. Increased nuclear translocation of $\beta$-catenin and interactions with TCF/LEF (T-cell factor/lymphoid enhancer binding factor) family proteins stimulate $\beta$-catenin-dependent gene expression, including cyclin D1, VEGF and COX-2, thereby increasing proliferation and growth. ${ }^{8}$

HAMLET (human $\alpha$-lactalbumin made lethal to tumour cells) consists of partially unfolded $\alpha$-lactalbumin and oleic acid and is the first member of a new family of tumouricidal unfolded protein-lipid complexes. ${ }^{9}$ HAMLET kills many types of tumour cells in vitro ${ }^{10}$ and this tumouricidal activity is maintained in vivo. ${ }^{11-13}$ Tumour cells are broadly sensitive to HAMLET, reflecting shared molecular features resulting from oncogenic transformation. ${ }^{14}$ In lung carcinoma cells, the sensitivity to HAMLET's tumouricidal effect reflected the level of c-Myc expression, and shRNA silencing of c-Myc or Ras pathway members conferred resistance to HAMLET. Furthermore, HAMLET sensitivity was reduced by shRNAs targeting glycolytic enzymes like hexokinase $1,{ }^{14}$ and by metabolomic analysis a rapid metabolic paralysis was detected in tumour cells after HAMLET treatment.

Examining whether HAMLET may be used for colon cancer treatment is logical, based on the properties of the complex and its biological context. The constituents of HAMLET are present in human milk, where the complex is formed after unfolding of the protein and hydrolysis of oleic acid from milk triglycerides. At low $\mathrm{pH}$, HAMLET may be assembled, for passage through the gastrointestinal tract of the breast-fed child. In vitro studies have shown that HAMLET is protease resistant, ${ }^{15}$ suggesting that by surviving the harsh gastrointestinal environment HAMLET may reach and kill cells that are sensitive to its effects, including colon cancer progenitors. This study investigated whether HAMLET acts as a colon cancer therapeutic agent, using peroral administration in the $A p c^{\mathrm{Min} /+}$ mouse model. In view of the stepwise tumour development taking place in this model, we also explored if HAMLET acts prophylactically in genetically susceptible mice. The results clearly demonstrate prophylactic and therapeutic effects of HAMLET, as well as effects on the Wnt/ $\beta$-catenin signalling pathway.

\section{METHODS}

\section{HAMLET production}

HAMLET was produced as described. ${ }^{16}$ Briefly, native $\alpha$-lactalbumin was purified from human milk by hydrophobic interaction chromatography. The protein was unfolded with EDTA, subjected to ion-exchange chromatography on a matrix preconditioned with oleic acid and eluted with a high salt concentration solution. HAMLET was lyophilised after purification and kept frozen until use.

\section{In vivo treatment with HAMLET}

$A p c^{\mathrm{Min} /+}$ mice were obtained from Jackson Laboratories. For the HAMLET therapeutic protocol, 8-10-week-old male mice were orally gavaged with $10 \mathrm{mg}$ of HAMLET in $400 \mu \mathrm{l}$ phosphate $=$ buffered saline (PBS), twice daily for 10 days. Mice were not given water or food for $5 \mathrm{~h}$ before HAMLET administration. Food and water were provided $30 \mathrm{~min}$ after HAMLET oral administration. Sham-treated mice were gavaged with $400 \mu \mathrm{l}$ PBS. Mice were killed 5 weeks after the end of HAMLET treatment and intestinal tissue samples were collected for further analysis. A similar treatment was used in the survival study groups where mice were observed until 40 weeks of age.

For HAMLET prophylaxis, 5-week-old $A p c^{\mathrm{Min} /+}$ mice were provided with HAMLET $(10 \mathrm{mg} /$ day $)$ in the drinking water for 10 weeks and killed at 15 weeks of age. The HAMLET dosage of $10 \mathrm{mg} / 400 \mu \mathrm{l}$ twice daily was selected based on positive results in previous clinical studies, where a concentration of $10 \mathrm{mg} / \mathrm{ml}$ was effective in topical application on skin papillomas $^{13}$ and $25 \mathrm{mg} / \mathrm{ml}$ for topical instillation in the urinary bladder where most of the substance is eliminated by voiding. ${ }^{12}$

All animal protocols and procedures were reviewed and approved by the institutional animal experimental ethics committee at the Lund District Court, Sweden.

\section{Tumour enumeration and sample collection}

Mice were killed by $\mathrm{CO}_{2}$ inhalation. The entire gastrointestinal tract was removed and kept in ice-cold PBS for dissection. The stomach and colon were not included in the analysis owing to low tumour incidence. The small intestine was cut into three equal-length segments. To remove intestinal contents, each segment was flushed with ice-cold PBS with the help of a gavage needle attached to a syringe. Each segment was kept on a filter paper and longitudinally opened. Tumour numbers and size were determined using a dissecting microscope (Olympus).

\section{In vivo HAMLET uptake}

After $5 \mathrm{~h}$ of starvation, mice were orally gavaged with $10 \mathrm{mg}$ HAMLET in $400 \mu \mathrm{l}$ PBS. After 2, 4 and $6 \mathrm{~h}$ of HAMLET administration, mice were killed with $\mathrm{CO}_{2}$ inhalation. To detect HAMLET in the intestinal lumen, $5 \mathrm{~cm}$ intestinal segments from the upper or lower small intestine were harvested and washed with $500 \mu \mathrm{l}$ of ice-cold PBS. Sodium dodecyl sulphate lysis buffer $(2 \%)$ was added in the intestinal washing, heated $(5 \mathrm{~min}$, $95^{\circ} \mathrm{C}$ ) and centrifuged at high speed for $10 \mathrm{~min}$. Supernatant was collected and used for western blotting for the detection of HAMLET using anti- $\alpha$-lactalbumin antibodies (GeneTex, Inc).

For the detection of HAMLET in tumour tissue, intestinal segments were flushed thoroughly $(5 \mathrm{ml} \mathrm{PBS}, \times 3)$ to remove luminal contents. Segments were longitudinally opened and again washed in PBS $(5 \mathrm{ml}$ PBS, $\times 3$ ). Tumour and healthy tissue were further used for western blot detection of HAMLET.

\section{Methylene blue staining}

The opened intestinal segments were spread flat between sheets of filter paper and fixed overnight in 10\% neutral buffered formalin. Formalin-fixed sections were transferred to $70 \%$ ethanol and stained with $0.2 \%$ methylene blue. Stained sections were rinsed in deionised water and imaged by dissecting microscope. 


\section{Cell transfection and luciferase assay}

For reporter gene assay, DLD1 cells were seeded in 96-well plates and a Cignal TCF/LEF Reporter (Luciferase) kit (SABiosciences) was used, according to manufacturer's recommendations.

\section{Holographic microscopy}

For phase holographic imaging, cells were cultured overnight in a tissue culture flask and treated with HAMLET. Images were captured at different time points from the same spot on the flask. The HoloMonitor M2 digital holographic microscope (Phase Holographic Imaging AB, Lund, Sweden) records the three-dimensional structure of cells by their exposure to $0.8 \mathrm{~mW} \mathrm{HeNe}$ laser $(633 \mathrm{~nm})$ using interfering wave fronts induction. The interference pattern was recorded as a hologram on a digital sensor.

\section{Statistics}

All in vitro experiments were repeated at least three times. Data are expressed as means \pm SEM. The differences between control and treatment groups were determined by analysis of variance followed by $t$ tests. Differences in survival were evaluated by Kaplan-Meier analysis with a log-rank (Mantel-Cox) test.

\section{Additional methods}

Additional methods are described in the online supplementary methods.

\section{RESULTS \\ HAMLET reduces intestinal tumour burden and increases survival}

HAMLET was administered perorally to tumour-bearing $A p c^{\mathrm{Min} /+}$ mice (8-10 weeks of age) and tumour development was assessed in tissues obtained 5 weeks after the end of treatment (figure 1A). Sham-fed mice receiving PBS as gavage were used as controls. Peroral HAMLET administration caused a significant reduction in the number of small intestinal tumours and in tumour size compared with sham-treated mice (figure 1B-E). In intestinal segments opened longitudinally, the total number of polyps was reduced by about $58 \%(\mathrm{p}<0.0001)$ (figure 1E). A reduction in polyp number and size was also evident in methylene blue-stained intestinal segments (figure 1C) and in haematoxylin and eosin-stained 'Swiss roll' sections (figure 1D). Intestinal villus hyperplasia was noticed in untreated mice but treated mice showed normal villi (see online supplementary figure S1). Importantly, the peroral HAMLET-treated $A p c^{M i n /+}$ mice showed significantly improved survival compared with sham-treated mice $(p=0.0103)$ (figure 1F). The frequency of

A

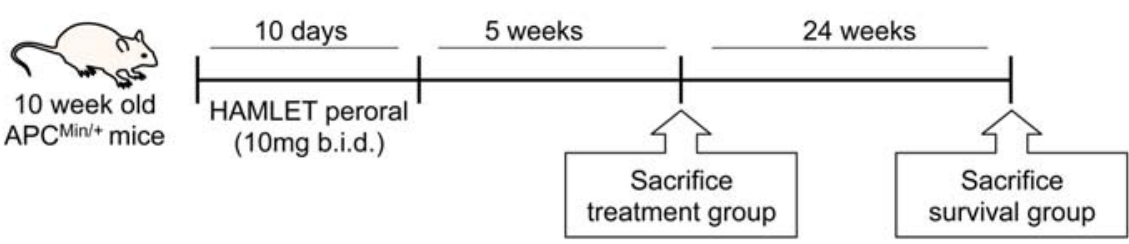

B

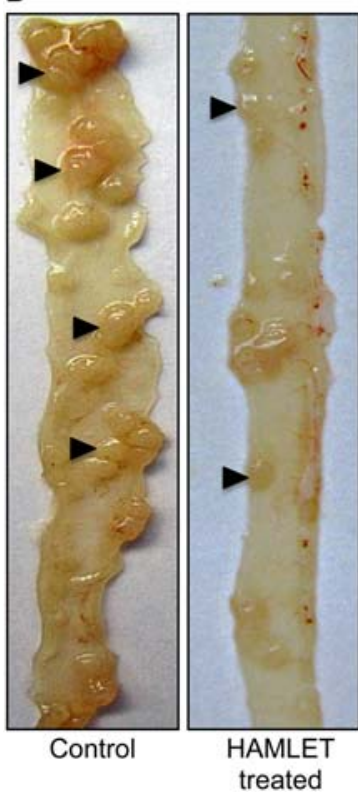

C

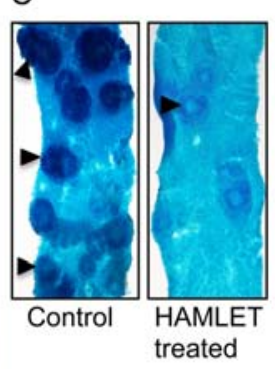

E

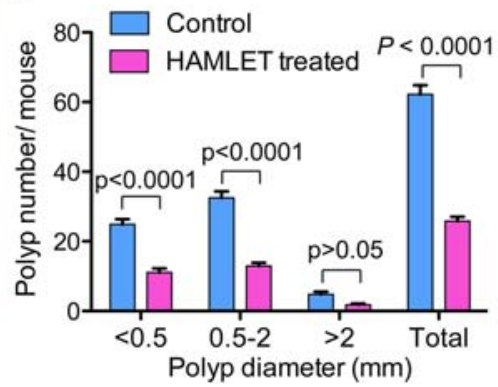

D

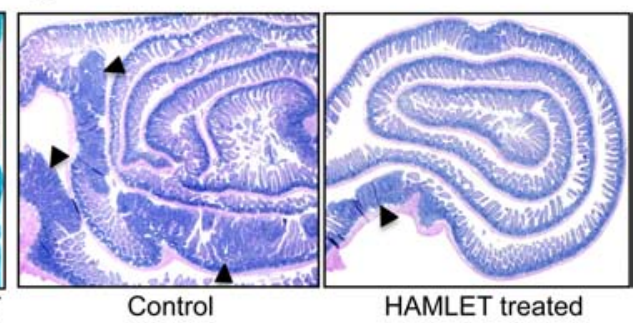

$\mathrm{F}$

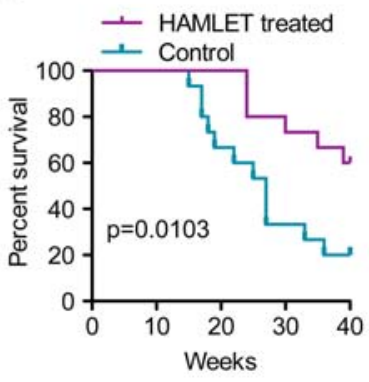

Figure 1 Human $\alpha$-lactalbumin made lethal to tumour cells (HAMLET) treatment reduces intestinal tumour progression and increases survival. (A) $\mathrm{Apc}^{\mathrm{Min} / \mathrm{+}}$ mice were treated orally with $10 \mathrm{mg}$ of HAMLET, twice daily for 10 days. The mice were killed 5 weeks after the end of treatment or observed for survival until 40 weeks of age. (B) Dissection photomicrographs of small intestinal segments showing tumours (arrowheads) in HAMLET-treated or control mice. (C) Methylene blue stained whole mounts of intestinal segments (arrowheads, tumours). (D) Haematoxylin and eosin stained intestinal Swiss roll sections showing smaller and fewer polyps in HAMLET-treated $A p c^{\text {Min/+ }}$ mice than in controls. (E) Quantification of the therapeutic effect on tumour number and size. A significant reduction of intestinal tumour load ( $p<0.0001$ for total tumour count) was seen in HAMLET-treated mice $(n=10)$ compared with sham-treated mice $(n=10)$ (two-way analysis of variance test). Error bars represent \pm SEM. $(F)$ KaplanMeier survival analysis. The end point was reached when mice were moribund or at 40 weeks. HAMLET-treated mice $(n=15)$ showed improved survival compared with sham-treated mice $(n=15) . p=0.0103$, log-rank (Mantel-Cox) test. 
colonic polyps is usually low in $A p c^{\mathrm{Min} /+}$ mice. ${ }^{17}$ As the frequency in this study was $<1$ lesion per mouse, no reliable comparisons between HAMLET-treated and sham-fed mice were made.

\section{Reduced levels of $\boldsymbol{\beta}$-catenin pathway proteins in treated tumours}

To examine if HAMLET modifies the $\mathrm{Wnt} / \beta$-catenin signalling pathway, $\beta$-catenin and $\beta$-catenin-regulated proteins were quantified in tumour biopsy specimens (figure $2 \mathrm{~A}$ ). $\beta$-Catenin staining was markedly reduced in HAMLET-treated tumour tissues compared with controls, and this difference was confirmed by western blotting on tumour tissue homogenates (figure 2B).

Furthermore, the expression of proteins downstream from $\beta$-catenin was also affected (figure 2A). Cyclin D1 staining was reduced in HAMLET-treated mice and this effect was confirmed by western blotting $(p=0.003)$. VEGF and COX-2 immunostaining and western blotting showed a similar decrease (figure $2 \mathrm{~A}, \mathrm{~B})$, and the results were confirmed by ELISA of tissue homogenates (figure 2D,E). Finally, a marked reduction in the frequency of Ki-67-positive cells $(p=0.001)$ suggested that HAMLET inhibits tumour cell proliferation (figure 2A,C).

\section{HAMLET targets tumour cells in vivo and is resistant to gastric enzymes}

The presence of HAMLET in tumour tissue was visualised in sections obtained $4 \mathrm{~h}$ after HAMLET administration. HAMLET was shown to accumulate in the tumours (figure $2 \mathrm{~F}$ ), with strong nuclear staining in individual tumour cells. In contrast, healthy cells adjacent to the tumour did not take up HAMLET. Differences in HAMLET content between tumours and healthy tissue were confirmed by western blotting (figure $2 \mathrm{G}$ ).

To examine if HAMLET resists proteolytic degradation in vivo, gastrointestinal contents harvested after HAMLET gavage were subjected to western blotting, using $\alpha$-lactalbumin-specific antibodies (figure $2 \mathrm{H}$ ). Bands of $14 \mathrm{kDa}$ were detected in the contents of the stomach and distal small intestine, $6 \mathrm{~h}$ after oral administration, suggesting that the HAMLET complex remains intact in the gastrointestinal tract.

\section{HAMLET modifies $\boldsymbol{\beta}$-catenin structure and localisation in colon cancer cells}

To further examine how HAMLET affects $\beta$-catenin and Wnt signalling, we used the human colon cancer cell line DLD1, carrying a homozygous mutation that inactivates the APC tumour suppressor. $^{18}$ The susceptibility to HAMLET was first assessed by real-time holographic imaging (figure $3 \mathrm{~A}$ ). A time-dependent decrease in cell area $(\mathrm{p}<0.0001)$ and an increase in maximum thickness were seen $(p<0.0001)$. The rapid reduction in viability was confirmed as a drop in ATP levels $(\mathrm{p}<0.01)$ and Presto blue staining $(p<0.001)$ (figure $3 \mathrm{~B})$.

A reduction in $\beta$-catenin, cyclin D1 and VEGF levels was detected by western blot analysis (figure 3C). By confocal microscopy, a rapid change in $\beta$-catenin distribution was also observed. Nuclear $\beta$-catenin staining was lost and cytoplasmic staining was reduced $(p<0.0001)$ (figure $3 \mathrm{D})$. To examine whether this loss of nuclear $\beta$-catenin influences gene expression, TCF/LEF reporter activity was quantified using the TOP-flash dual luciferase assay. A dose-dependent reduction in luciferase levels was detected $(\mathrm{p}<0.05)$ (figure $3 \mathrm{E}$ ).

In parallel, $\beta$-catenin was shown to accumulate at the cytoplasmic membrane (figure 3D,F). As $\beta$-catenin binds to the intracellular domain of E-cadherin, ${ }^{19}$ HAMLET-treated cells were double-stained. Specific colocalisation of $\beta$-catenin and E-cadherin was detected at the cytoplasmic membrane in HAMLET-treated cells but not in control cells (figure 3F). By E-cadherin pull-down, an increase in bound $\beta$-catenin was detected, confirming this interaction (see online supplementary figure S2). E-cadherin expression remained unchanged after HAMLET treatment (see online supplementary figure S3).

Significant $\beta$-catenin fragmentation was also detected in HAMLET-treated DLD1 cells (figure 4A,B). As caspase-3dependent $\beta$-catenin fragmentation has been reported, ${ }^{20}$ caspase-3 activation was quantified (see online supplementary figure S4). Rapid activation of caspase-3 was detected and inhibition by zVAD confirmed the involvement in $\beta$-catenin fragmentation (figure 4C). The calpain inhibitor leupeptin had no effect. HAMLET did not significantly affect p-GSK $3 \alpha / \beta$ which phosphorylates $\beta$-catenin for proteasomal degradation ${ }^{21}$ (see online supplementary figure S5). Zhao et $a l^{22}$ recently reported that AMP-activated protein kinase (AMPK) responds to the loss of ATP by phosphorylating $\beta$-catenin. We therefore examined if HAMLET alters AMPK expression, but found no change after $3 \mathrm{~h}$ (see online supplementary figure S6). Treatment with $\alpha$-lactalbumin alone showed no effect on cellular ATP levels in DLD1 cells (see online supplementary figure S7A). Moreover, $\alpha$-lactalbumin or oleic acid treatment failed to induce any significant differential expression of genes in DLD1 cells (see online supplementary figure S7B).

\section{Ion fluxes triggered by HAMLET explain effects on $\boldsymbol{\beta}$-catenin}

Ion channels support oncogenic transformation, ${ }^{23}$ and in other tumour cells, we have observed that specific ion fluxes activated by HAMLET explain many aspects of the tumouricidal response (Storm et al, unpublished). To further examine the mechanism of $\beta$-catenin fragmentation, DLD1 cells were pretreated with the ion channel inhibitors amiloride or barium chloride $\left(\mathrm{BaCl}_{2}\right)$. Both inhibitors blocked $\beta$-catenin fragmentation (figure $4 \mathrm{C}$ ), the activation of caspase-3 (figure 4D) and the loss of nuclear $\beta$-catenin (figure 4E). In comparison, zVAD only affected nuclear $\beta$-catenin levels in about $30 \%$ of the cells, suggesting that while ion fluxes may activate caspase-dependent mechanisms, caspase-independent mechanisms are also involved (see online supplementary figure S8). Furthermore, cell death was prevented by the ion channel blockers $(p<0.001)$ but not by $\mathrm{zVAD}$ (figure $4 \mathrm{~F}$ ). The activation of ion fluxes by HAMLET was confirmed in DLD1 cells preloaded with $\mathrm{Ca}^{2+}$ or $\mathrm{K}^{+}$fluorophores (figure 4G).

The effects of HAMLET on cell viability and the fragmentation of $\beta$-catenin were confirmed in SW480 colon cancer cells carrying the APC mutations (see online supplementary figure S9).

\section{HAMLET acts as a prophylactic agent against intestinal cancer}

To examine if HAMLET may be used prophylactically, the drinking water of $A p c^{\mathrm{Min} /+}$ mice was supplemented with HAMLET (10 mg/mouse) daily, from the time of weaning until 15 weeks of age (figure 5A). A marked reduction in tumour development was seen compared with controls receiving nonsupplemented drinking water. A significant reduction in the number and size of polyps was seen $(p<0.0001)$ (figure $5 B-D)$. Haematoxylin and eosin staining of 'Swiss roll' sections confirmed these differences (see online supplementary figure S10). In tumour biopsies (figure $5 \mathrm{E}$ ), $\beta$-catenin staining was reduced by HAMLET as was cyclin D1 and COX-2 staining, confirming effects seen in the therapeutic group (figure 2). 
A

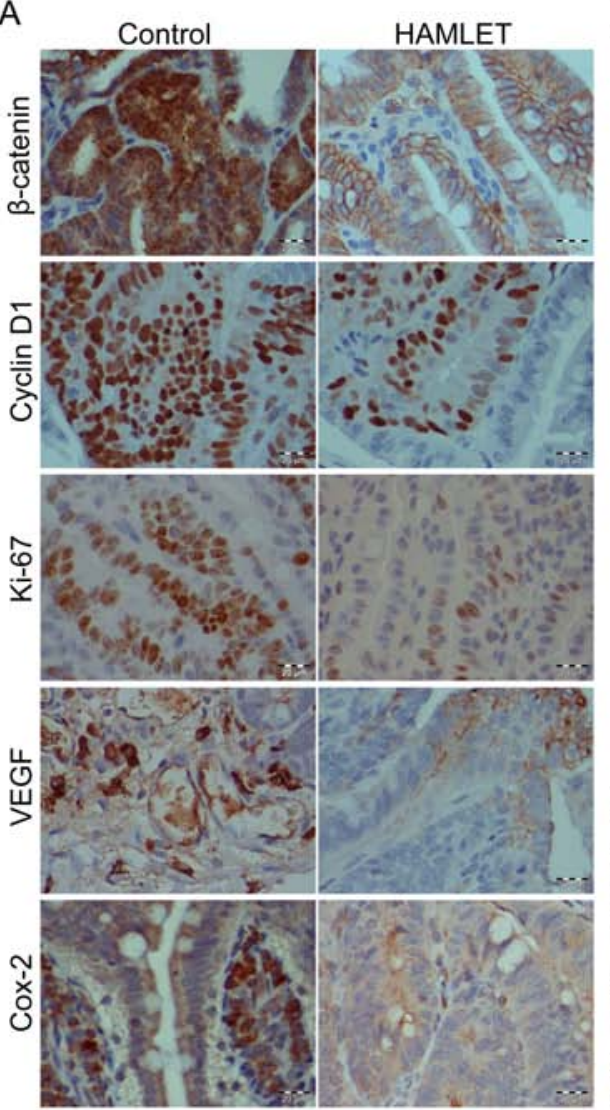

F Normal Normal
B
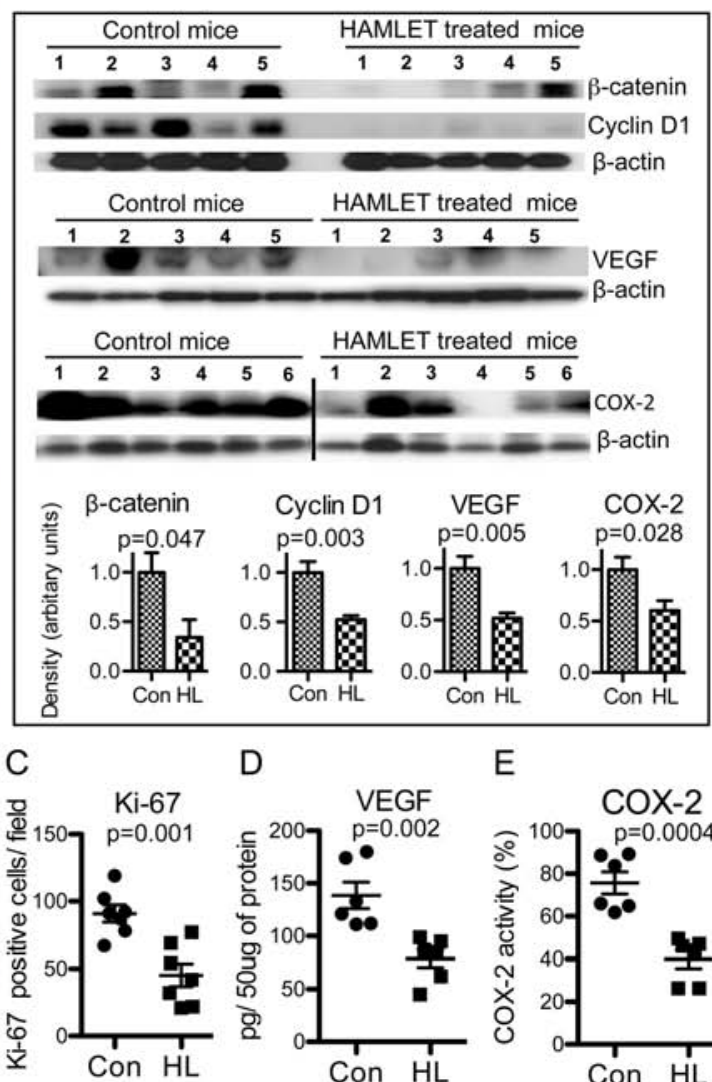

D

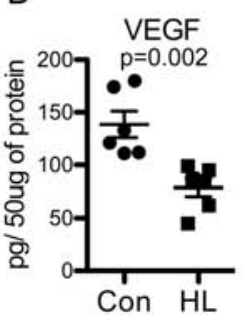

$\mathrm{E}$

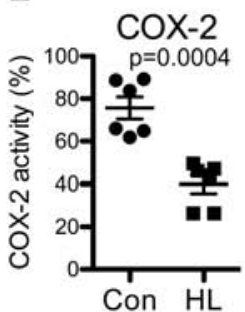

Figure 2 Selective human $\alpha$-lactalbumin made lethal to tumour cells (HAMLET) uptake and reduced $\beta$-catenin pathway proteins and proliferation markers. (A) Representative immunostained sections demonstrating reduced $\beta$-catenin, cyclin D1, Ki-67, VEGF and COX-2 levels in tumours from HAMLET-treated compared with sham-treated mice (scale bars, $20 \mu \mathrm{m})$. (B) Western blots confirming significant reduction of $\beta$-catenin ( $p=0.047)$, cyclin D1 ( $p=0.003)$, VEGF $(p=0.005)$ and COX-2 ( $p=0.028)$. Histograms show the mean densitometry values for the blots of each protein $(t$ test, $n=5-6)$. (C) Quantification of Ki-67 positive cells ( $t$ test, $n=5)$. (D, E) Quantification of VEGF and COX-2 activity in tumour lysates by ELISA shows significant reduction ( $t$ test, $n=6$ ). (F) Representative immunostaining showing HAMLET uptake (arrowheads, intense HAMLET staining) by tumour tissue, $4 \mathrm{~h}$ after HAMLET treatment (left and middle scale bars, $500 \mu \mathrm{m}$; right, $20 \mu \mathrm{m}$ ). Neighbouring healthy tissue (arrow) shows low HAMLET uptake. Some crypt cells show weak nuclear HAMLET staining, suggesting a low degree of uptake by these rapidly proliferating, healthy cells. (G) Quantification of HAMLET uptake by western blots of small intestinal lysates. Small intestinal tumour tissues show higher HAMLET content than the healthy tissue. $\beta$-actin was the loading control. USI, upper small intestine; DSI, distal small intestine. (H) Stability of HAMLET in the intestine. After oral HAMLET gavage $(2,4$ and $6 \mathrm{~h}$ ), luminal contents were collected from the stomach and small intestinal segments for western blotting using anti- $\alpha$-lactalbumin antibody. In all panels, error bars represent \pm SEM. 


\section{A}
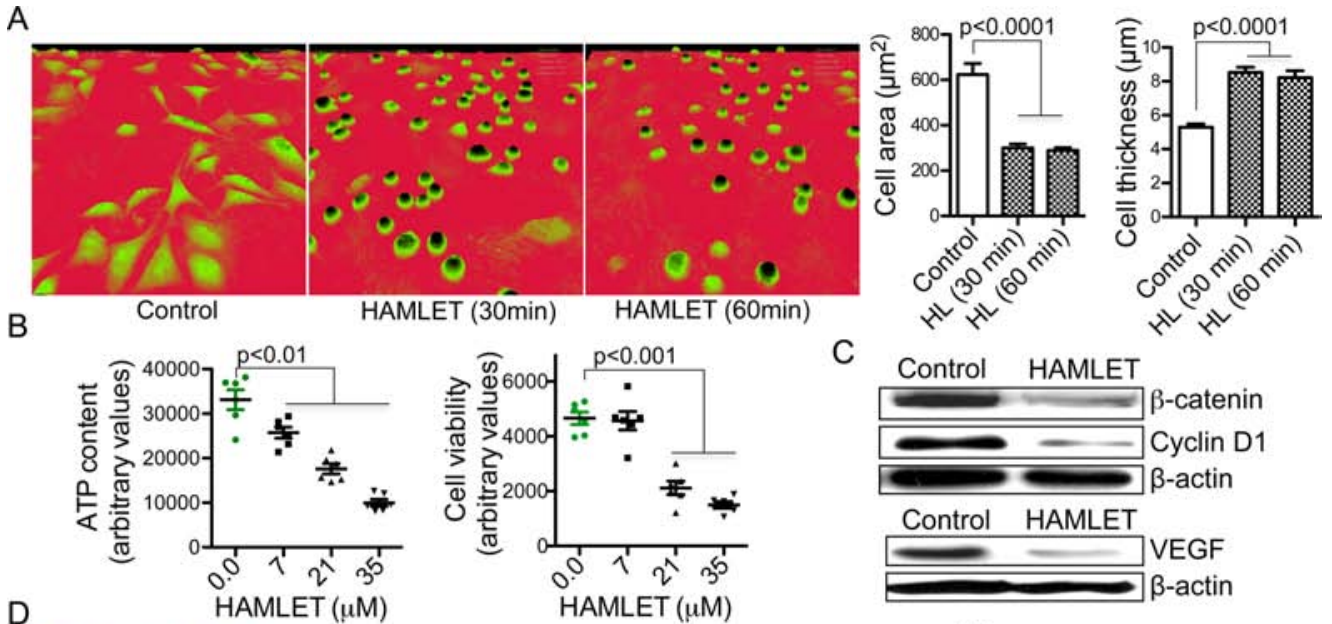

C

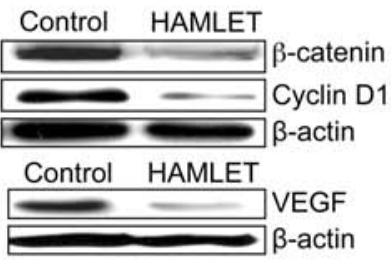

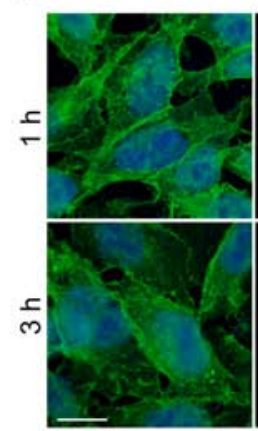

Control

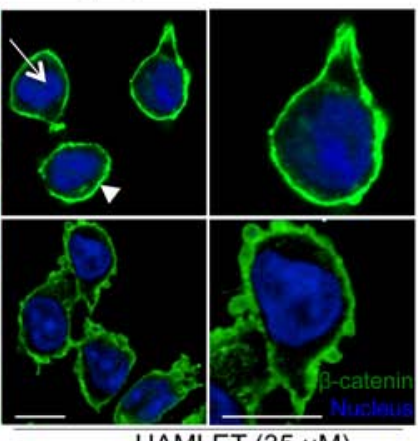

$\operatorname{HAMLET}(35 \mu \mathrm{M})$

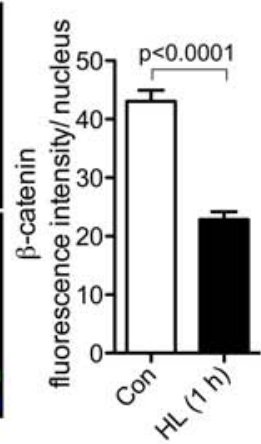

$\mathrm{E}$

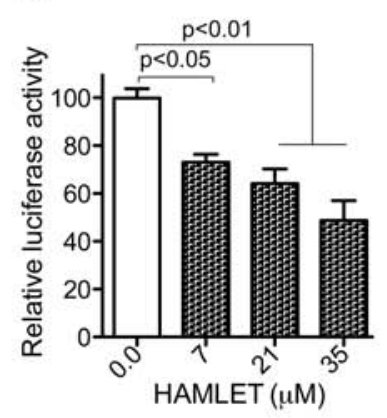

F
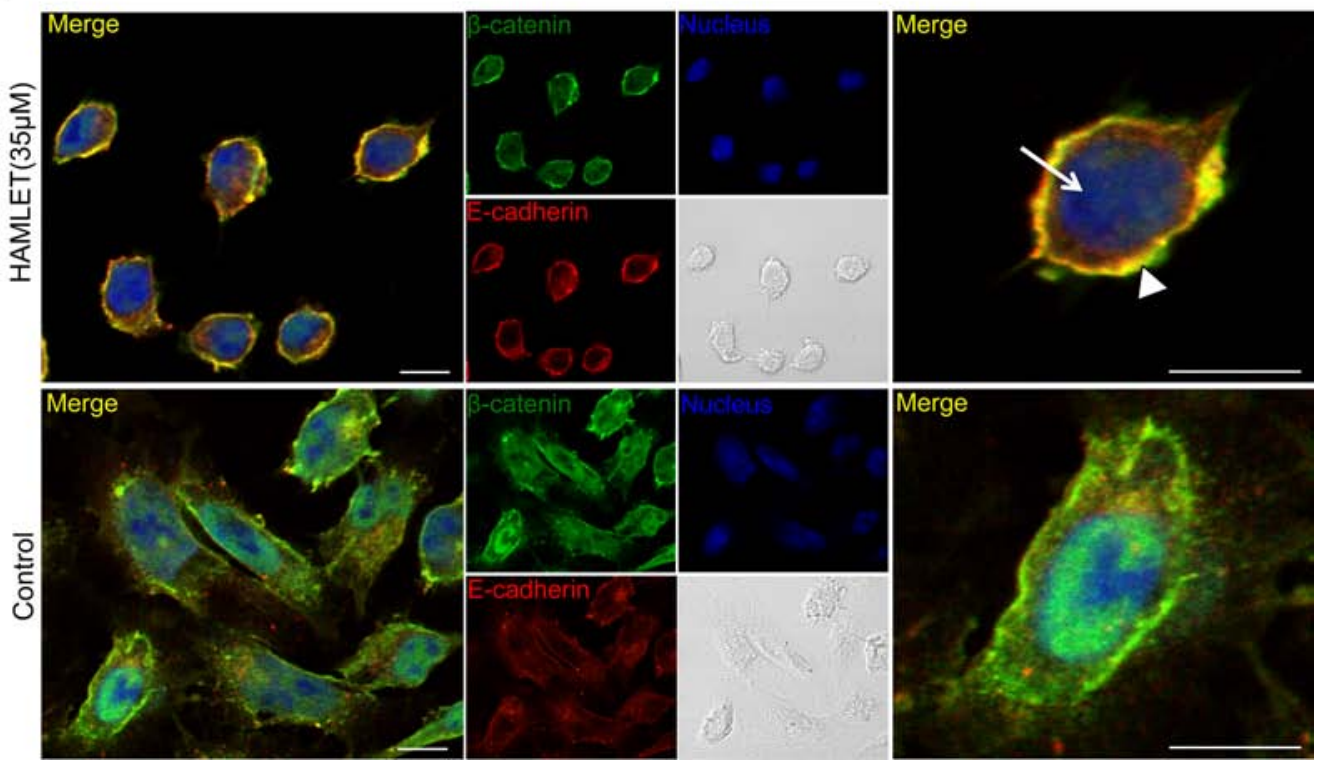

Figure 3 Effects of human $\alpha$-lactalbumin made lethal to tumour cells (HAMLET) on Wnt/B-catenin pathway in vitro. APC mutated, DLD1 human colon cancer cells were exposed to HAMLET. (A) Time-dependent morphological changes, detected by phase contrast holographic microscopy. Significant reduction in surface area $(p<0.0001)$ and increase in thickness $(p<0.0001)$ are quantified (one-way analysis of variance $(A N O V A)$ test, $n=3)$. (B) Dose-dependent loss of viability after HAMLET treatment $(3 \mathrm{~h})$, quantified by ATP measurements $(p<0.01)$ and Presto blue $(p<0.001)$ (one-way ANOVA test, $n=3$ ). (C) Decrease in $\beta$-catenin, cyclin D1 and VEGF protein levels after HAMLET treatment $(3 \mathrm{~h}, 35 \mu \mathrm{M})$. Western blot, with $\beta$-actin as loading control. (D) DLD1 cell monolayers were treated with HAMLET (35 $\mu \mathrm{M}, 1$ and $3 \mathrm{~h}$ ), fixed and immunostained for $\beta$-catenin (green). Nuclei were counterstained with DRAQ5 (blue). HAMLET significantly reduced nuclear $\beta$-catenin staining in treated cells $(p<0.0001)(t$ test, $n=3)$. The uniform cytoplasmic staining was replaced by strong membrane staining (scale bars, $10 \mu \mathrm{m}$ ). (E) TCF/LEF (T-cell factor/lymphoid enhancer binding factor) reporter activity quantified by TOP-flash dual luciferase assay. A dose-dependent reduction in luciferase activity was detected after $3 \mathrm{~h}$ of HAMLET treatment $(p<0.01$ and $p<0.05)$ (one-way analysis of variance test, $n=3$ ). (F) HAMLET enhances colocalisation of $\beta$-catenin and E-cadherin on the cell membrane. Cells exposed to HAMLET $(35 \mu \mathrm{M}, 3 \mathrm{~h})$ were double stained for $\beta$-catenin (green), E-cadherin (red) and DRAQ5 (blue) as a nuclear staining agent. Both $\beta$-catenin and E-cadherin were intensely colocalised at the cell membrane with increase in $\beta$-catenin staining (scale bars, $10 \mu \mathrm{m})$. In all panels, error bars represent \pm SEM. 
A

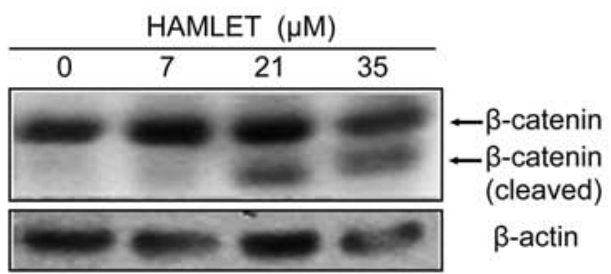

B

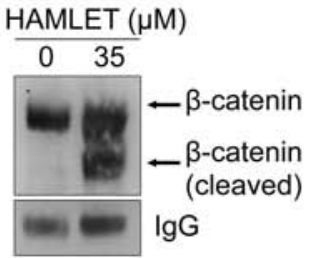

C

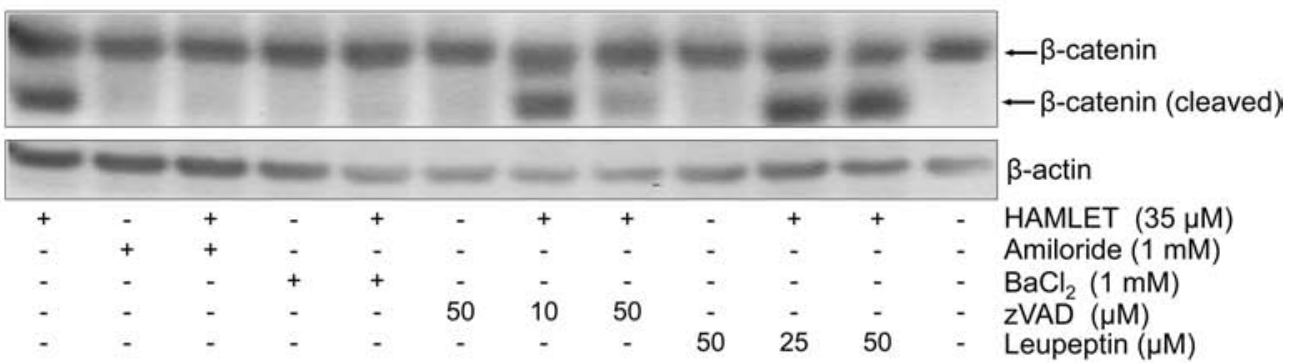

D
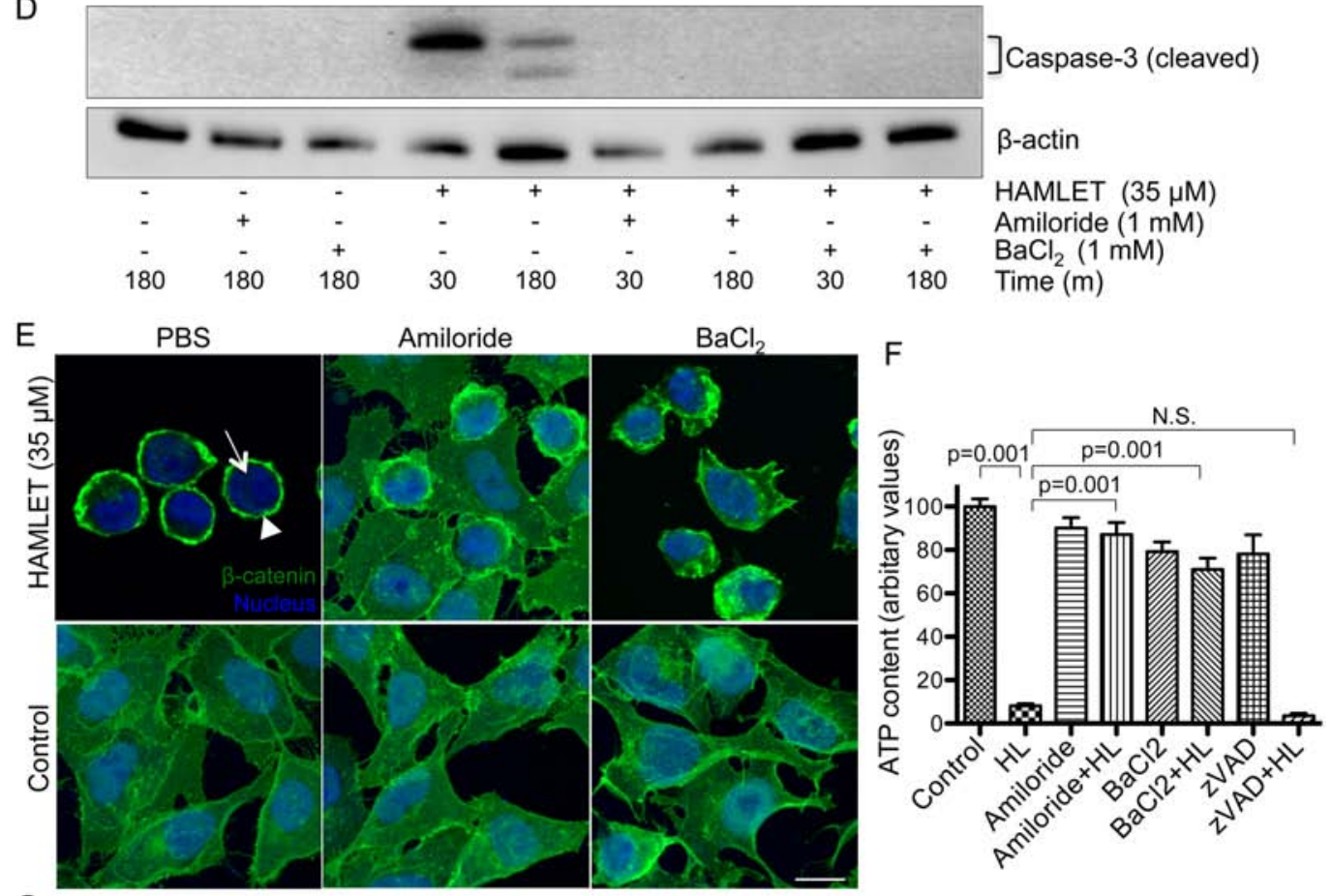

G
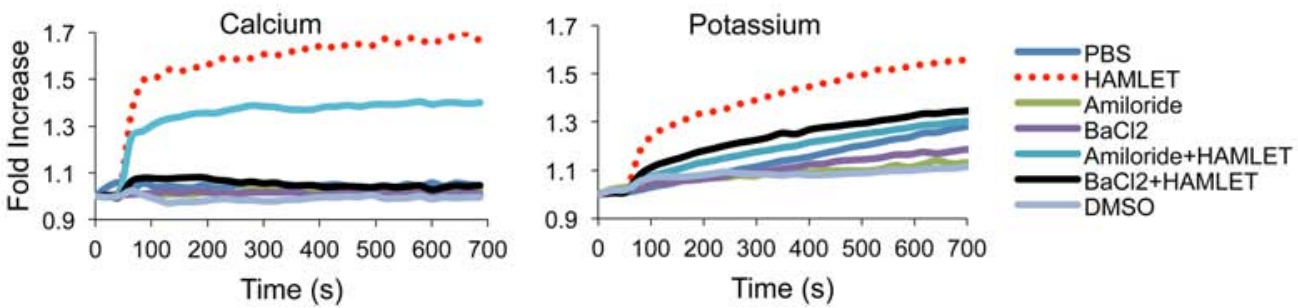

Figure 4 Ion channel-dependent degradation and nuclear translocation of $\beta$-catenin in human colon cancer cells DLD1. (A) Dose-dependent degradation of $\beta$-catenin in DLD1 cells after human $\alpha$-lactalbumin made lethal to tumour cells (HAMLET) treatment ( $3 \mathrm{~h}$ ). $\beta$-actin was the loading control. (B) Immunoprecipitation of HAMLET-treated cells $(35 \mu \mathrm{M}, 1 \mathrm{~h})$. $\beta$-catenin was pulled down and subjected to western blot. Cleavage of $\beta$-catenin was seen after HAMLET treatment. (C) DLD1 cells were pretreated with ion channel inhibitors (amiloride and $\mathrm{BaCl}_{2}$ ), caspases $(\mathrm{zVAD})$ or calpain (leupeptin) as indicated and subsequently HAMLET-treated ( $35 \mu \mathrm{M}, 1 \mathrm{~h})$. Ion channel inhibitors completely, and zVAD partially, abrogated HAMLET-induced $\beta$-catenin cleavage but not leupeptin. (D) Western blot demonstrating ion channel-dependent caspase activation by HAMLET. Ion channels inhibitors (amiloride and $\mathrm{BaCl}_{2}$ ) completely abrogated HAMLET-induced caspase-3 activation. (E) HAMLET-induced ( $35 \mu \mathrm{M}, 1 \mathrm{~h}$ ) loss of nuclear $\beta$-catenin staining (green) was prevented by pretreatment with ion channel inhibitors amiloride and $\mathrm{BaCl}_{2}$. Nuclei are stained blue with DRAQ5 (scale bars, $10 \mu \mathrm{m})$. ( $F$ ) Ion channel inhibitors prevent HAMLET-induced cell death $(\mathrm{p}<0.001)$ (one-way analysis of variance test, $\mathrm{n}=3$ ). (G) HAMLET induced calcium and potassium fluxes in fluorophore-loaded DLD1 cells that were abrogated by amiloride and $\mathrm{BaCl}_{2}$. Error bars represent \pm SEM. 
A

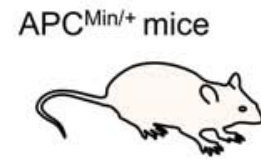

immediately after weaning

10 weeks

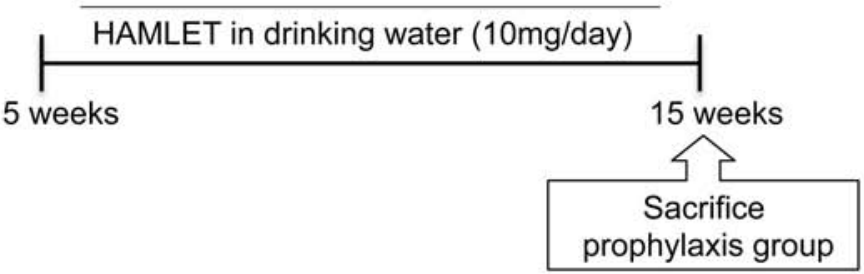

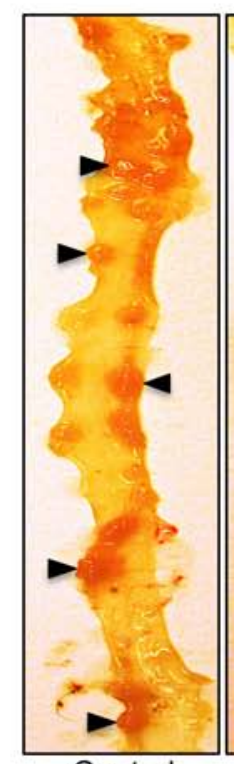

Control

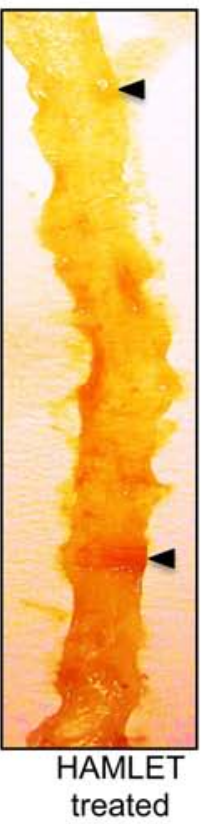

C

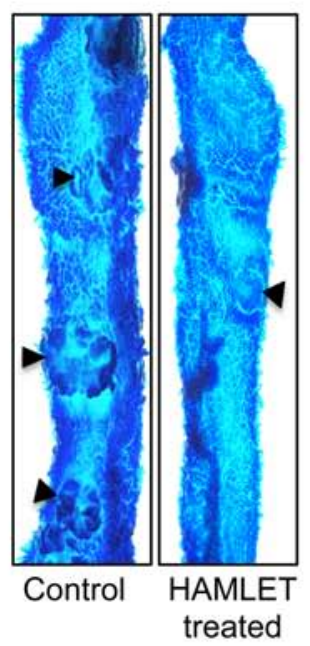

D

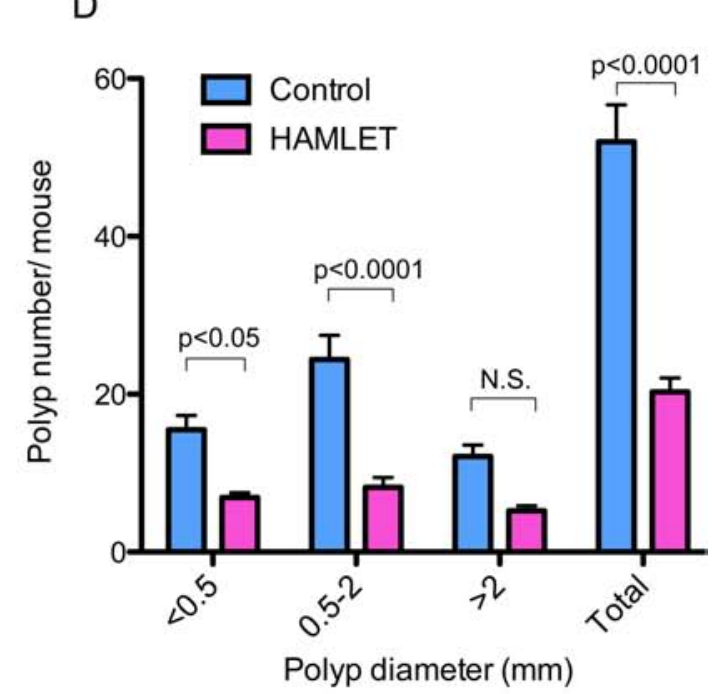

E
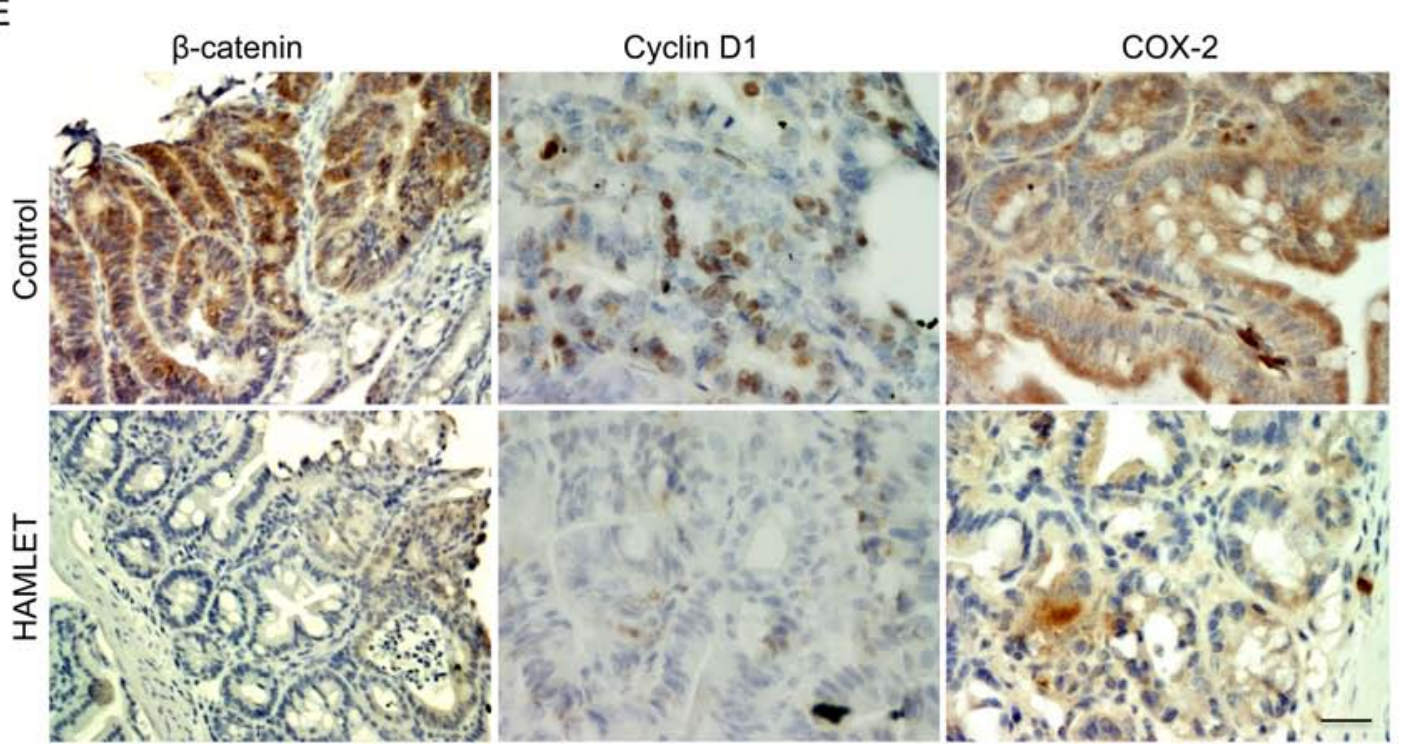

Figure 5 Human $\alpha$-lactalbumin made lethal to tumour cells (HAMLET) prophylaxis reduces intestinal tumour development. (A) Apc ${ }^{\text {Min/+ }}$ mice were provided with HAMLET (10 mg/day) supplemented in the drinking water for 10 weeks and killed at 15 weeks of age. (B) Dissection

photomicrographs of small intestinal segments showing prevention of tumour development (arrowheads) in HAMLET-treated mice $(n=10)$ compared with sham-treated mice $(n=10)$. (C) Methylene blue-stained whole mounts of intestinal segments shows reduced tumour (arrowheads) load in HAMLET-treated mice. (D) Quantification of the tumour number and size after HAMLET prophylaxis. HAMLET-treated mice $(n=10)$ showed significant reduction ( $p<0.0001$ for total tumour count) compared with sham-treated mice $(n=10)$ (two-way analysis of variance test). Error bars represent \pm SEM. (E) Representative immunostained sections demonstrating reduced $\beta$-catenin, cyclin D1 and COX-2 levels in HAMLET-treated tumours compared with mock-treated tumours (scale bars, $20 \mu \mathrm{m}$ ). 


\section{Gene expression profiling in tumours remaining after prophylaxis/treatment}

To examine how HAMLET modifies the gene expression profile in vivo, tumours recovered from HAMLET-treated or control mice were characterised by whole-genome transcriptional profiling (figure 6). After HAMLET prophylaxis, marked differences in gene expression were seen (figure 6A). Using a stringent cut-off point of false discovery rate (FDR)-adjusted $\mathrm{p}$ value $<0.05$ and $\log 2(\mathrm{FC})>1,224$ unique genes (125 upregulated and 99 downregulated) were differentially expressed.

By gene set enrichment analysis (GSEA, figure 6B and see online supplementary figure S11), HAMLET was shown to decrease the expression of genes in the $\beta$-catenin signalling pathway $(\mathrm{p}=0.002)$. DNA-replication genes were also inhibited $(p=0.002)$, (figure 6B).

Gene sets enriched in HAMLET-treated tumours included oxidative phosphorylation $(\mathrm{p}=0.001)$ and glycolysis $(\mathrm{p}=0.013)$ as well as glutathione metabolism $(p=0.001)$, (figure $6 \mathrm{C})$. Importantly, a coordinated upregulation of almost all genes necessary for glycolysis was seen after HAMLET treatment, with the most significant being fructose-1,6-bisphosphatase, glucose-6phosphatase and lactate dehydrogenase. In addition, a scatterplot analysis indicated a coordinated increase in a large number of genes involved in oxidative phosphorylation $(p<0.001)$ (figure $6 \mathrm{D})$, an increased conversion of glucose into pyruvate and increased ATP synthesis, suggesting a departure from the 'Warburg phenotype' in tumour cells surviving HAMLET treatment. Furthermore, a number of glutathione S-transferases and enzymes were also more highly expressed, as were detoxifying compounds that protect against oxidative stress by conjugation of glutathiones. Upregulated genes in the oxidative phosphorylation machinery included both ATPases, NADH dehydrogenases and cytochrome $\mathrm{c}$ oxidase, indicating a general increase of activity in this pathway.

HAMLET was also identified as a regulator of several transcription factors (figure 6E). CTNNB1 ( $\beta$-catenin) was negatively regulated, with six downstream transcripts showing decreased expression (TNFRSF11B, SPP1, SERPINE1, MMP7, IGFBP5 and CYP51A1), consistent with the GSEA. Transcription factors regulating the defence against reactive oxygen species were upregulated (NFE2L2, NR1I3 and NR1I2). HAMLET also stimulated HNF4, which drives the expression of lipolytic enzymes that might be needed to metabolise oleic acid in HAMLET-treated cells (figure 6E).

Significant effects of HAMLET on gene expression were also seen in the therapeutic group compared with sham-fed controls (see online supplementary figure S12A). The most highly expressed genes were involved in glucose metabolism, including a large fraction of key enzymes responsible for glycolytic fluxes (see online supplementary figures S12B-D and 13, ingenuity $p$ value $10^{-9}$ and GSEA FDR q value 0.05 ). In addition, negative regulators of the Wnt signalling pathway were enriched (q values 0.032 ). Wnt inhibitory factor 1 was upregulated twofold as was SOX17 ( (sex determining region Y)-box 17), which modulates Wnt signalling through binding to Wnt3A.

We conclude that peroral prophylactic and therapeutic effects of HAMLET are accompanied by a well-defined series of stable changes in gene expression, affecting Wnt signalling and $\beta$-catenin, as well as glycolysis, oxidative phosphorylation and lipid metabolism in tumour tissues.

\section{DISCUSSION}

Colorectal cancer is the second leading cause of cancer-related deaths in the USA and more than 160000 cases are diagnosed annually. ${ }^{2}$ A significant number of people inherit the susceptibility to colon cancer. ${ }^{4}$ Despite repeated, often invasive diagnostic and therapeutic procedures, many develop the disease. ${ }^{4}$ In this study, the prophylactic and therapeutic effects of HAMLET against colon cancer, together with a clear demonstration of inhibition of $\beta$-catenin signaling, are therefore of great potential significance. $A p c^{\mathrm{Min} /+}$ mice were used as a model of human disease, and spontaneous, age-related tumour development was drastically reduced after peroral HAMLET prophylaxis. In addition, the number and size of intestinal tumours as well as associated mortality were reduced by peroral HAMLET administration to mice with established tumours. These effects were accompanied by changes in Wnt/ $\beta$-catenin signaling, and gene expression analysis suggested that surviving tumour cells had been routed to a more benign phenotype with reduced Wnt signalling and increased aerobic glycolysis. HAMLET thus offers a new approach to colon cancer treatment, acting by removing established tumour cells and preventing tumour development in the intestinal mucosa. We propose that peroral HAMLET administration should be tested clinically, especially in families bearing APC gene mutations.

Aberrant activation of $\mathrm{Wnt} / \beta$-catenin signalling is fundamental to the pathogenesis of colon cancer, and molecular control of this pathway has become a major therapeutic focus. ${ }^{8} 24$ In normal cells, proteasomal $\beta$-catenin degradation proceeds through the formation of a destruction complex, limiting nuclear translocation and transcription of $\beta$-catenin-dependent genes. In colon cancer cells, $\beta$-catenin degradation is impaired and nuclear translocation is enhanced, leaving the Wnt-signalling pathway overactive and the cells tumour prone. Extracellular Wnt inhibitors, including the secreted frizzled-related proteins, have been pursued as potential therapeutic agents, ${ }^{25}$ and small molecular antagonists of the protein-protein interaction between $\beta$-catenin and transcription TCFs have shown encouraging preclinical results. ${ }^{26}$ In addition, numerous epidemiological studies have detected benefits of non-steroidal anti-inflammatory drugs ${ }^{27}$ with a molecular mechanism recently linked to inhibition of nuclear accumulation of $\beta$-catenin. ${ }^{28}$ In response to HAMLET, $\beta$-catenin was proteolytically cleaved and the nuclear $\beta$-catenin content was markedly reduced. The remaining polypose tissue from HAMLET-treated mice showed a reduction in staining of $\beta$-catenin, VEGF and COX- 2 as well as proliferation markers cyclin D1 and Ki-67. These findings identify HAMLET as a new Wnt pathway modifier, acting by reducing nuclear $\beta$-catenin accumulation and $\beta$-catenin-dependent gene expression.

Rapid activation of ion fluxes has recently been proposed as a unifying mechanism of tumour cell death in response to HAMLET (Storm et al, unpublished). Inhibitors blocking $\mathrm{Na}^{+}$ and $\mathrm{K}^{+}$fluxes were shown to rescue tumour cells from death and in addition, the inhibitors blocked HAMLET internalisation, changed gene expression, mitogen-activated protein kinase (MAPK) signalling and the stress response to HAMLET (Storm et al, unpublished). In this study, HAMLET-dependent ion channel activation was shown also to control the change in $\beta$-catenin structure and function, caused by HAMLET. These effects were executed, in part, via caspase-3 activation but the fragmentation and the relocation of $\beta$-catenin from the nuclei to the cell periphery required ion channel activation. Caspase-3-dependent $\beta$-catenin fragmentation has previously been described in colon cancer cells, based on inhibition by zVAD. ${ }^{29}$ Furthermore, HAMLET has been shown to activate caspase- 3 in tumour cells ${ }^{30}$ but the functional importance of this response has been unclear, as caspase inhibition does not prevent the cytotoxic response to HAMLET. Importantly, HAMLET treatment did not alter the levels of phosphorylated or total GSK3, indicating that 
A

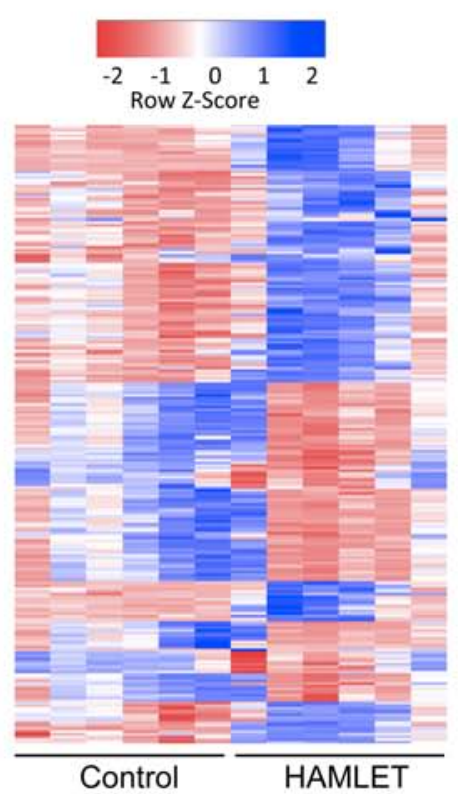

B

Gene sets suppressed by HAMLET
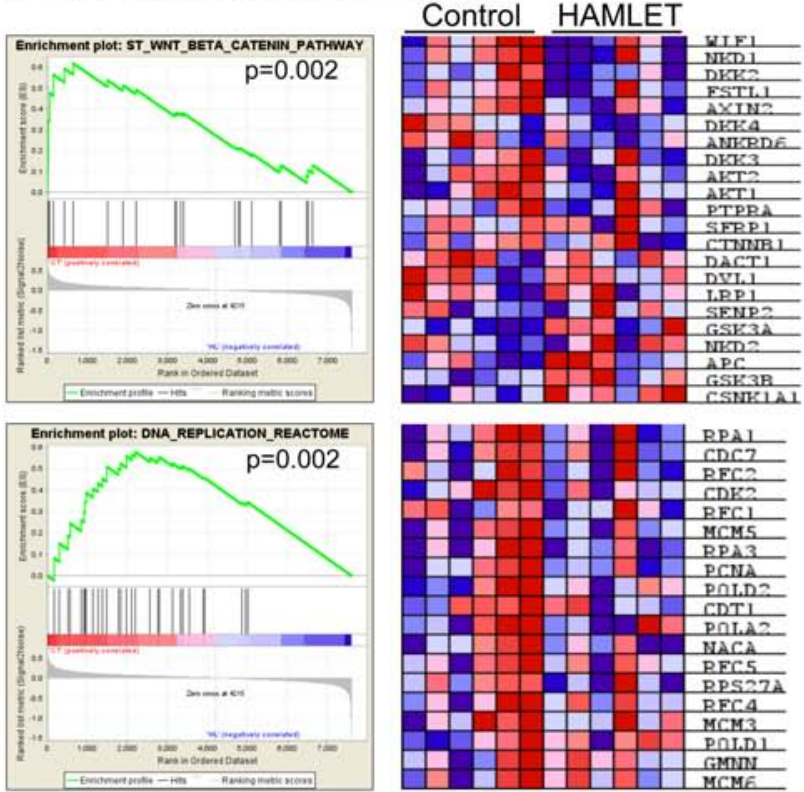

C

Gene sets enriched by HAMLET
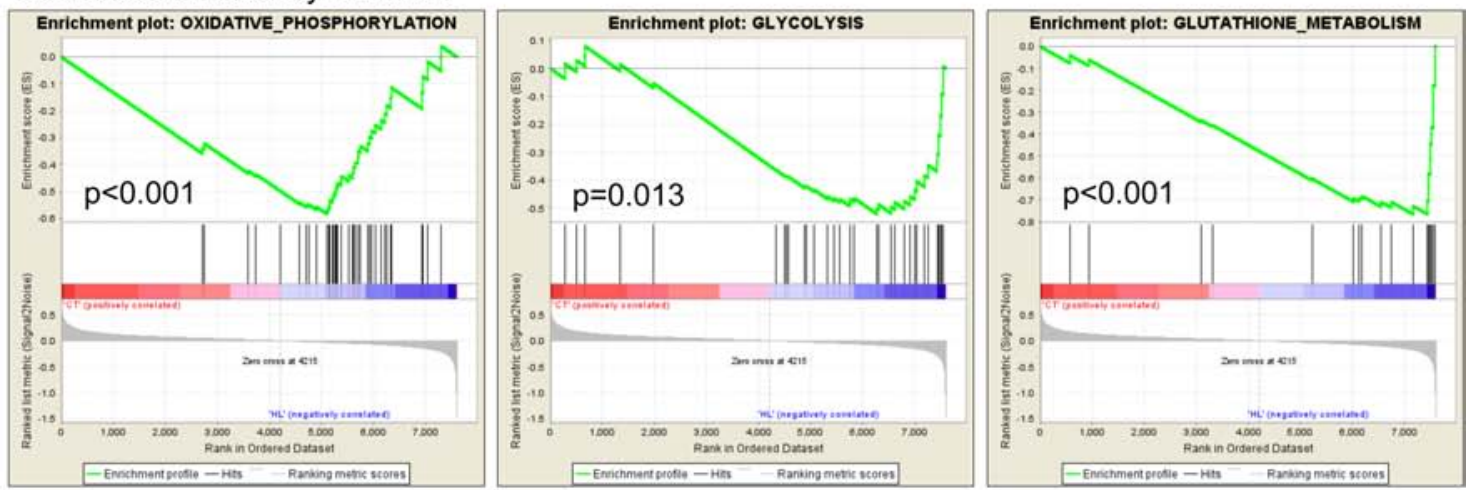

D

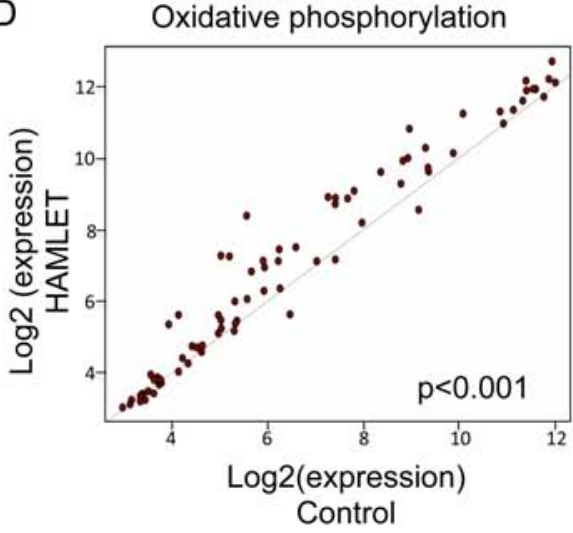

$\mathrm{E}$

\begin{tabular}{|c|c|c|c|}
\hline $\begin{array}{l}\text { Transcription } \\
\text { Regulator }\end{array}$ & $\begin{array}{l}\text { Predicted } \\
\text { Activation } \\
\text { State }\end{array}$ & z-score & $\mathrm{p}$-value \\
\hline CTNNB1 & Inhibited & -2.08 & $9.18 \mathrm{E}-04$ \\
\hline TP53 & Inhibited & -2.11 & $1.06 \mathrm{E}-02$ \\
\hline STAT5B & Inhibited & -2.20 & $7.13 \mathrm{E}-02$ \\
\hline ATF4 & Inhibited & -2.22 & 3.90E-02 \\
\hline NFE2L2 & Activated & 2.93 & $1.31 \mathrm{E}-05$ \\
\hline NR1/3 & Activated & 2.53 & $6.13 \mathrm{E}-12$ \\
\hline NR1/2 & Activated & 2.21 & $9.74 \mathrm{E}-11$ \\
\hline HNF4A & Activated & 2.08 & $4.73 \mathrm{E}-01$ \\
\hline
\end{tabular}

Figure 6 Whole-genome profiling identifying distinct transcriptional events in tumours after human $\alpha$-lactalbumin made lethal to tumour cells (HAMLET) prophylaxis. (A) Heat map of differentially expressed genes (log 2 fold change $>1$ and false discovery rate (FDR)-adjusted $p$ value $<0.05$, $\mathrm{n}=224$ ) between HAMLET and mock treated tumours, indicating that there are distinct differences between the two groups. (B) Gene sets depleted by HAMLET treatment included $\beta$-catenin and DNA replication pathways. Heat maps shows expression of individual genes for each tumour. See also online supplementary figure S8. (C) Expression of genes involved in oxidative phosphorylation $(p<0.001)$, glycolysis $(p=0.013)$ and glutathione metabolism $(p<0.001)$ were enriched after HAMLET treatment. (D) Scatterplot visualisation of genes in the oxidative phosphorylation pathway showing a coordinated increase in expression of almost all genes after HAMLET treatment $(p<0.001)$. (E) Ingenuity Pathway Analysis highlighting suppressed and enhanced transcription factors. $\beta$-Catenin (CTNNB1) signalling is inhibited in HAMLET-treated tumours. 
HAMLET is not modulating downstream components of the Wnt pathway by this mechanism. These findings suggest that in addition to the effects on $\beta$-catenin signalling, HAMLET triggers a Wnt-independent, ion channel-dependent mechanism controlling $\beta$-catenin in colon cancer cells. In addition, we suggest that caspase- 3 functions as an effector of $\beta$-catenin fragmentation in HAMLET-treated tumour cells.

Gene expression analysis detected short-term and long-term effects of HAMLET in vivo consistent with the effects seen at protein level. After HAMLET prophylaxis, surviving tumours showed a marked reduction in $\beta$-catenin-dependent gene expression. Aerobic glycolysis was enhanced, consistent with a suppression of the Warburg phenotype, which was identified by shRNA screening as one of the essential determinants of HAMLET sensitivity in tumour cells. ${ }^{14}$ Furthermore, glutathione signalling was activated, indicating an oxidative stress response. A similar but less complete change in gene expression was seen in the therapeutic group, where the expression of Wnt signalling inhibitors was enhanced combined with a general stimulation of genes involved in glycolysis.

Gene expression analysis of the tissue samples from the prophylactic group detected a reduction in $\beta$-catenin gene expression, suggesting that the $\beta$-catenin-driven tumour development might be delayed compared with development in the sham-fed controls. In the therapeutic group that received HAMLET after tumours were established, no decrease in $\beta$-catenin expression was seen but an increase in Wnt signalling inhibitors was detected, compared with fully developed tumours. This may suggest that different mechanisms account for the shift in $\beta$-catenin function in cells surviving HAMLET challenge during prophylaxis or treatment. These studies suggest that HAMLET drives a gradual loss of the malignant phenotype and a gain of more normal cellular functions. The mechanism is not clear, but we speculate that an enrichment of more differentiated cells may result from purging by HAMLET of the most malignant and HAMLET-sensitive cells. In addition, a redirection of the cellular machinery towards a more differentiated phenotype may occur.

The lack of selectivity for tumour tissue is a major concern in colon cancer treatment and side effects are often severe. HAMLET is formed from beneficial human milk constituents and has previously been shown to preferentially kill tumour cells rather than healthy, differentiated cells. Our study provides further in vivo evidence for HAMLET's tumour selectivity. By comparing adjacent areas of tumour tissues and healthy tissues in individual $A p c^{\mathrm{Min} /+}$ mice, HAMLET was shown to reach intestinal polyps and to be internalised selectively by tumour cells. There was no evidence of toxicity or inflammatory changes in healthy tissue, suggesting that side effects to peroral HAMLET treatment may be limited. Furthermore, these observations are of particular interest, as they suggest that the APC mutation alone does not render intestinal cells sensitive to HAMLET. While all cells in these mice carry the $A p c^{\mathrm{Min} /+}$ mutation, it is well established that colorectal tumour development involves the sequential accumulation of oncogenic mutations, including KRAS, c-myc and p53. The point at which tumours become sensitive to HAMLET may reveal at which point of tumour development cells become sensitive to the cytotoxic and therapeutic effects of HAMLET. The selective uptake of HAMLET into tumour tissue and reduction in malignancy is encouraging for the development of future therapeutic tools against colon cancer.

Acknowledgements We thank Susan Basiri, Anki Mossberg and James Ho (BMC, Lund University) for their assistance in HAMLET production; Majlis Svensson, Tina Gustavsson and Anna Rydström (BMC, Lund University) for their help with animal experiments and Bryndis Rgnarsdottir for critically reading the paper.
Contributors MP and CS conceived the study and designed the experiments. MP conducted most of the in vivo experiments and analysed the data. MP and AN performed in vitro experiments, western blotting, immunostaining and microscopy. SH helped in E-cadherin immunostaining and confocal microscopy. PS performed the transcriptomic analysis of tumour tissues. MP, AN and CS analysed the in vitro data. $\mathrm{CS}$ and MP wrote the manuscript with contributions from PS. All authors read and agreed on the final manuscript.

Funding The financial support from A*STAR, Singapore during the early phase of the project is gratefully acknowledged. This study was supported by the Sharon D Lund foundation grant and the American Cancer Society, the Swedish Cancer Society, the Medical Faculty (Lund University), the Söderberg Foundation, the Segerfalk Foundation, the Anna-Lisa and Sven-Erik Lundgren Foundation for Medical Research, the Knut and Alice Wallenberg Foundation, the Lund City Jubileumsfond, the John and Augusta Persson Foundation for Medical Research, the Maggie Stephens Foundation, the Gunnar Nilsson Cancer Foundation, the Inga-Britt and Arne Lundberg Foundation, the HJ Forssman Foundation for Medical Research and the Royal Physiographic Society.

Competing interests This study received no financial support from any commercial organisations. CS is a shareholder in HAMLET Pharma, a currently inactive company holding the patent rights to HAMLET.

\section{Patient consent Obtained.}

Provenance and peer review Not commissioned; externally peer reviewed.

Open Access: This is an Open Access article distributed in accordance with the Creative Commons Attribution Non Commercial (CC BY-NC 3.0) license, which permits others to distribute, remix, adapt, build upon this work non-commercially, and license their derivative works on different terms, provided the original work is properly cited and the use is non-commercial. See: http://creativecommons.org/ licenses/by-nc/3.0/

\section{REFERENCES}

1 Gangadhar T, Schilsky RL. Molecular markers to individualize adjuvant therapy for colon cancer. Nat Rev Clin Oncol 2010;7:318-25.

2 Siegel R, Ward E, Brawley 0, et al. Cancer statistics, 2011: the impact of eliminating socioeconomic and racial disparities on premature cancer deaths. $C A$ Cancer J Clin 2011:61:212-36.

3 Markowitz SD, Bertagnolli MM. Molecular origins of cancer: Molecular basis of colorectal cancer. N Engl J Med 2009;361:2449-60.

4 Vogelstein B, Fearon ER, Hamilton SR, et al. Genetic alterations during colorectal-tumor development. N Engl J Med 1988;319:525-32.

5 Moser AR, Pitot HC, Dove WF. A dominant mutation that predisposes to multiple intestinal neoplasia in the mouse. Science 1990;247:322-4.

6 Clevers H. Wnt/beta-catenin signaling in development and disease. Cell 2006;127:469-80.

7 Moon RT, Bowerman B, Boutros $M$, et al. The promise and perils of Wnt signaling through beta-catenin. Science 2002;296:1644-6.

8 Bienz $\mathrm{M}$, Clevers $\mathrm{H}$. Linking colorectal cancer to Wnt signaling. Cell 2000;103:311-20.

9 Pettersson-Kastberg J, Aits S, Gustafsson L, et al. Can misfolded proteins be beneficial? The HAMLET case. Ann Med 2009;41:162-76.

10 Svanborg C, Agerstam H, Aronson A, et al. HAMLET kills tumor cells by an apoptosis-like mechanism-cellular, molecular, and therapeutic aspects. Adv Cancer Res 2003;88:1-29.

11 Fischer W, Gustafsson L, Mossberg AK, et al. Human alpha-lactalbumin made lethal to tumor cells (HAMLET) kills human glioblastoma cells in brain xenografts by an apoptosis-like mechanism and prolongs survival. Cancer Res 2004;64:2105-12.

12 Mossberg AK, Wullt B, Gustafsson L, et al. Bladder cancers respond to intravesical instillation of HAMLET (human alpha-lactalbumin made lethal to tumor cells). IntJ Cancer 2007:121:1352-9.

13 Gustafsson L, Leijonhufvud I, Aronsson A, et al. Treatment of skin papillomas with topical alpha-lactalbumin-oleic acid. N Engl J Med 2004;350:2663-72.

14 Storm P, Aits S, Puthia MK, et al. Conserved features of cancer cells define their sensitivity to HAMLET-induced death; c-Myc and glycolysis. Oncogene 2011:30:4765-79.

15 Gustafsson L, Aits S, Onnerfjord P, et al. Changes in proteasome structure and function caused by HAMLET in tumor cells. PloS One 2009:4:e5229.

16 Svensson M, Hakansson A, Mossberg AK, et al. Conversion of alpha-lactalbumin to a protein inducing apoptosis. Proc Natl Acad Sci USA 2000;97:4221-6.

17 Koehl GE, Spitzner M, Ousingsawat J, et al. Rapamycin inhibits oncogenic intestinal ion channels and neoplasia in $A p c^{\text {Min/+ }}$ mice. Oncogene 2010;29:1553-60.

18 Ilyas M, Tomlinson IP, Rowan A, et al. Beta-catenin mutations in cell lines established from human colorectal cancers. Proc Natl Acad Sci USA 1997:94:10330-4. 


\section{Colon}

19 Aberle H, Butz S, Stappert J, et al. Assembly of the cadherin-catenin complex in vitro with recombinant proteins. J Cell Sci 1994;107:3655-63.

20 Steinhusen U, Badock V, Bauer A, et al. Apoptosis-induced cleavage of beta-catenin by caspase-3 results in proteolytic fragments with reduced transactivation potential. J Biol Chem 2000;275:16345-53.

21 Ikeda S, Kishida M, Matsuura Y, et al. GSK-3beta-dependent phosphorylation of adenomatous polyposis coli gene product can be modulated by beta-catenin and protein phosphatase 2A complexed with Axin. Oncogene 2000;19:537-45.

22 Zhao J, Yue W, Zhu MJ, et al. AMP-activated protein kinase (AMPK) cross-talks with canonical Wnt signaling via phosphorylation of beta-catenin at Ser 552 . Biochem Biophys Res Commun 2010;395:146-51.

23 Kunzelmann K. Ion channels and cancer. J Membr Biol 2005;205:159-73.

24 Segditsas S, Tomlinson I. Colorectal cancer and genetic alterations in the Wnt pathway. Oncogene 2006;25:7531-7.
25 Kawano Y, Kypta R. Secreted antagonists of the Wnt signalling pathway. I Cell SCi 2003;116:2627-34.

26 Lepourcelet M, Chen YN, France DS, et al. Small-molecule antagonists of the oncogenic Tcf/beta-catenin protein complex. Cancer Cell 2004;5:91-102.

27 Thun MJ, Namboodiri MM, Heath CW Jr. Aspirin use and reduced risk of fatal colon cancer. N Engl J Med 1991;325:1593-6.

28 Greenspan EJ, Madigan JP, Boardman LA, et al. Ibuprofen inhibits activation of nuclear \{beta\}-catenin in human colon adenomas and induces the phosphorylation of GSK-3\{beta\}. Cancer Prev Res (Phila) 2011;4:161-71.

29 Fukuda K. Apoptosis-associated cleavage of beta-catenin in human colon cancer and rat hepatoma cells. Int I Biochem Cell Biol 1999;31:519-29.

30 Hallgren $\mathrm{O}$, Aits $\mathrm{S}$, Brest $\mathrm{P}$, et al. Apoptosis and tumor cell death in response to HAMLET (human alpha-lactalbumin made lethal to tumor cells). Adv Exp Med Biol 2008;606:217-40. 